\title{
Épocas de aplicação de ureias associadas à de nicosulfuron em híbridos de milho
}

\section{Urea timing of application associated to nicosulfuron in corn hybrids}

\author{
Heitor Franco de Sousa \\ Universidade Federal de Jataí \\ E-mail: hfsfranco@live.com \\ OrclD: https://orcid.org/0000-0002-8698-2783
}

Paulo César Timossi

Universidade Federal de Jataí

E-mail: ptimossi2004@yahoo.com.br

OrcID: https://orcid.org/0000-0002-0627-0672

Edésio Fialho dos Reis

Universidade Federal de Jataí

E-mail: edesiofr7@gmail.com

OrclD: https://orcid.org/0000-0002-8000-3513

Guilherme Braga Pereira Braz

Universidade de Rio Verde

E-mail: quilhermebrag@gmail.com

OrclD: https://orcid.org/0000-0002-0396-7140

Resumo: A adubação nitrogenada próxima à da aplicação de nicosulfuron ainda é considerada uma preocupação na agricultura. Essa associação pode ocasionar redução no crescimento e produtividade final de grãos. A necessidade de estudo sobre essa associação é extremamente importante. Sendo assim, objetivouse avaliar a associação de períodos de aplicação de ureia e ureia revestida à de nicosulfuron em híbridos de milho. Adotou-se delineamento de blocos casualizados em arranjo fatorial e adicionaram-se duas testemunhas: ureia e ureia revestida aplicadas no estágio fenológico V4, sem aplicação de herbicida e três repetições. Um fator corresponde ao tipo de ureia (Ureia e Ureia revestida) e outro ao período de aplicação das fontes de nitrogênio $(\mathrm{N})$ de acordo com a aplicação de nicosulfuron no estágio fenológico V4 (quatro (-4), dois (-2) dias antes, no mesmo dia (0), dois (2) e quatro (4) dias depois da aplicação de nicosulfuron). Os híbridos MG 30A37, DOW 2B610 e DKB 310 apresentaram uma porcentagem de retardo negativa significativa para altura de planta, em outras palavras, as plantas submetidas à associação obtiveram uma altura superior às da testemunha. Somente para o tratamento controle do comprimento de espiga e semente do AS 1633 que diferiram da combinação de fatores, sendo superiores. Houve um incremento na produtividade final de grãos para todos os híbridos com aplicação de ambas as fontes $\mathrm{N}$ no intervalo de dois dias antes da aplicação do herbicida a dois dias depois da aplicação do herbicida.

Palavras-chave: Acetolactato sintase. Fitointoxicação. Hormesis. Ureia revestida.

Abstract: Nitrogen fertilizers applied near to nicosulfuron still being a concern in agriculture. This association might cause reduce growth and final grain yield. The need of study over this association is extremely important, thus aimed to evaluate the association of urea and coated urea timing of application to nicosulfuron in corn hybrids. Set up a randomized complete block design in a factorial scheme and added two control treatments urea and coated urea applied at corn stage V4 without any herbicide and three replication. One factor correspond to type of urea (urea and coated urea) and other to timing of nitrogen application according to nicosulfuron application at corn stage $\mathrm{V} 4$ (four $(-4)$, two $(-2)$ days before, at the same day (0), two (2) and four (4) days after nicosulfuron). The hybrids MG 30A37, DOW 2B610 and DKB 310 showed a significant negative percentage of delaying growth, in other words, the plants submitted to the association were higher than the plants in the control treatments. Only the control treatment from cob and seed length of AS 1633 differed from the combination of factors and being superior. There was an increment on final grain production 
for all hybrids in both nitrogen source, between two days before herbicide application and two days after herbicide application.

Keywords: Acetolactate syntase. Phytointoxication. Hormesis. Coated urea.

Data de recebimento: 06/06/2018

Data de aprovação: 04/10/2020

DOI: https://doi.org/10.30612/agrarian.v14i51.8265

\section{Introdução}

Desde que empresas do setor agrícola desenvolveram moléculas químicas ou herbicidas com objetivo de controlar de plantas infestantes, indesejáveis ou daninhas em uma lavoura (Gerhardt, 2016), herbicidas do grupo químico das sulfonilureias tornaram-se opção para tanto na cultura do milho.

O nicosulfuron é um herbicida das sulfonilureias que inibe a enzima ALS (acetolactato sintase) responsável pela síntese de aminoácidos alifáticos de cadeia longa (Spatt et al., 2016), sendo utilizado para o controle de plantas daninhas anuais e perenes. O herbicida é seletivo para a cultura do milho no controle de gramíneas como Pennisetum setosum (Timossi et al., 2016), Sorghum halepense (Hernández et al., 2015), Digitaria insularis e Cenchrus echinatus (Timossi, 2009). Contudo, há híbridos de milho que possuem sensibilidade ao nicosulfuron, causando injúrias de fitointoxicação (Cavalieri et al., 2008). Além disso, as injúrias podem ser ainda maiores caso haja adubação de cobertura nitrogenada simultânea à do herbicida (López-Ovejero et al., 2003).

Em estudo com uso de fonte nitrogenada de liberação rápida aplicada próximo à de nicosulfuron, houve ausência de fitointoxicação, além das variáveis altura de plantas, peso de 1000 grãos e rendimento de grãos não terem sido afetadas significativamente (Nicolai et al., 2006). Por outro lado, estudo com as formulações de nicosulfuron mostrou que Sanson ${ }^{\circledR}$ aplicado no mesmo dia da adubação nitrogenada proporcionou fitointoxicação mais elevada, afetando negativamente o teor de clorofila e altura de plantas (Guerra et al., 2010). Ainda não há estudos com relação à aplicação de fontes nitrogenadas de liberação lenta próxima à aplicação do herbicida nicosulfuron. Além do mais, a necessidade de um estudo mais aprofundado sobre essa sensibilidade ao herbicida nicosulfuron é de extrema importância devido ao aumento de plantas daninhas resistentes a herbicidas (Heap, 2021).

A partir deste contexto, objetivou-se avaliar o efeito da adubação com ureia e ureia revestida próximo a aplicação de nicosulfuron em híbridos de milho.

\section{Material e Métodos}

Experimentos em campo foram conduzidos na área experimental da Universidade Federal de Jataí ( $17^{\circ} 55^{\prime} 32^{\prime \prime} \mathrm{S}$ e $\left.51^{\circ} 42^{\prime} 32^{\prime \prime} \mathrm{O}\right)$ em um Latossolo Vermelho distroférrico com textura argilosa (Santos et al., 2013), com $21,5 \%$ de areia, $11,1 \%$ de silte, $67,4 \%$ de argila, $37,9 \mathrm{~g} \mathrm{~kg}^{-1}$ de matéria orgânica e CTC de 10,1 $\mathrm{cmol}_{\mathrm{c}} \mathrm{dm}^{-3}$.

Adotou-se o delineamento de blocos casualizados com tratamentos em fatorial e três repetições. Os fatores correspondem ao tipo de ureia (ureia e ureia revestida com inibidora de urease) e ao período de aplicação de ureia (quatro (-4), dois (-2) dias antes, no mesmo dia (0), dois (2) e quatro (4) dias após a aplicação de nicosulfuron). Adicionaram-se dois tratamentos testemunha, sendo a aplicação de ureia e ureia revestida no estágio fenológico V4 sem aplicação de herbicida.

O nicosulfuron foi aplicado no estágio fenológico V4 no período da manhã, por um pulverizador costal pressurizado por $\mathrm{CO}_{2}$, com quatro pontas espaçadas a $0,5 \mathrm{~m}$ entre si, bicos tipo TT 110015, pressão a 2 bar, consumo de calda de $200 \mathrm{~L} \mathrm{ha}^{-1}$ e $1,1 \mathrm{~L}$ do ingrediente ativo (i.a.) ha-1 e formulação utilizada Sanson $40 \mathrm{SC}^{\circledR}$. Utilizaram-se $400 \mathrm{~kg} \mathrm{ha}^{-1}$ do fertilizante 08-20-18 na adubação de semeadura e para cada ureia (especificar a porcentagem de $\mathrm{N}$ na ureia) aplicaram-se $88 \mathrm{~kg} \mathrm{ha}^{-1}$ de $\mathrm{N}$ para obtenção de $120 \mathrm{~kg} \mathrm{ha}^{-1}$ de nitrogênio, $80 \mathrm{~kg}$ $\mathrm{ha}^{-1}$ de $\mathrm{P}_{2} \mathrm{O}_{5}$ e $72 \mathrm{~kg} \mathrm{ha}^{-1}$ de $\mathrm{K}_{2} \mathrm{O}$. A ureia e ureia revestida foram pesadas por balança de precisão e aplicadas manualmente. Os híbridos semeados foram DKB 310 (ciclo normal e híbrido simples), MG 30 A37 (ciclo precoce e híbrido duplo), AS 1633 (Ciclo precoce e híbrido simples) e DOW 2B610 (Ciclo precoce e híbrido simples), cada híbrido com três linhas de plantio (0,45 m entre linhas) e $6 \mathrm{~m}$ de comprimento. 
As variáveis analisadas foram a fitointoxicação, aos 7 e 14 dias depois da aplicação do herbicida (DDH), de acordo com escala do EWRC (1964). Para a porcentagem de retardo no crescimento, aos 21 e 35 $\mathrm{DDH}$, um segundo ensaio foi instalado no mesmo período de semeadura, com os mesmos tratamentos e tamanho de parcela, sem a aplicação de herbicida e o cálculo foi de acordo com a fórmula $\left(\left[Y_{i j}=Z_{i} \times 100 / X_{i}\right]\right.$ 1100) em que $Z_{i}$ corresponde à média da altura de plantas com aplicação de nicosulfuron na i observação e $X_{i}$ corresponde à média da altura de plantas sem aplicação de herbicida na j observação.

O diâmetro de colmo foi medido através de um paquímetro digital e medindo-se o colmo de oito plantas a $10 \mathrm{~cm}$ acima da superfície do solo. O comprimento de espiga foi determinado pela medição de cinco espigas por uma fita métrica em centímetros. O número de fileiras foi obtido pela contagem das fileiras de cinco espigas. A massa de 500 grãos foi determinada pela pesagem dos grãos centrais de cinco espigas. $O$ comprimento de grãos determinado pela medição central, por um paquímetro digital, da espiga com e sem semente, depois dividiu-se por dois o valor da diferença. A produtividade de grãos resultou da pesagem total dos grãos colhidos e corrigidos a $13 \%$ de umidade dentro dos $5 \mathrm{~m}$ da área útil de cada parcela.

Somente para a fitointoxicação realizou-se a análise descritiva, sendo que para as demais variáveis os dados foram submetidos ao teste de Levene para homogeneidade (variância dos resíduos são iguais). Caso não apresentassem homogeneidade, foram transformados em hiperbólica de primeiro ou segundo grau $\left(\mathrm{H} 1^{\circ}\right.$ ou $\mathrm{H}^{\circ}$ ), posteriormente submetidos a análise de variância (ANOVA) com $p<0,05$ e, caso significativo, a comparação entre as médias foi através o teste de Fisher LSD com $p<0,05$. Para todas as variáveis houve a comparação entre a combinação dos fatores (fatorial) e as testemunhas, sendo a diferença significativa quando apresentada nas tabelas pelo símbolo (\#). Também, realizou-se análise de regressão da produção final de grãos em função do período de aplicação de ureia e ureia revestida. Todas a análises estatísticas foram realizadas no programa $\mathrm{R}$ versão 3.3 .3 e utilizando-se o pacote Agricolae.

\section{Resultados e Discussão}

$\mathrm{Na}$ avaliação de fitointoxicação (dados não apresentados) aos 7 e $14 \mathrm{DDH}$, todos os híbridos não apresentaram fitointoxicação aos $14 \mathrm{DDH}$, assim mostrando uma tolerância à molécula. As novas tecnologias introduzidas nos híbridos atualmente, podem estar favorecendo a tolerância ao nicosulfuron, assim tornando a ação do citocromo P-450 e a glutationa-S-transferase mais rápida na metabolização da molécula e/ou no metabolismo xenobiótico (Fonné-Pfister e Kreus, 1990; Kreus e Fonné-Pfister, 1992).

Houve efeito na porcentagem de retardo no crescimento aos 21 e $35 \mathrm{DDH}$ (Tabela 2). Mesmo que os híbridos mostraram tolerância à molécula, esse efeito deve-se à concentração ou a translocação da molécula ser maior na parte apical das plantas (Gallaher et al., 1999). Possivelmente, a pequena concentração foi suficiente para ocorrer uma supressão de células (Môro e Damião Filho, 1999). Observou-se porcentagem de retardo negativa, isso ocorreu, pois onde houve aplicação de nicosulfuron as plantas foram superiores às que não foram submetidas ao herbicida (Tabelas 1 e 2). O híbrido MG 30A37 obteve a melhor resposta aos 21 DDH com a associação de ureia e nicosulfuron (-6,83\%), enquanto que AS 1633, DKB 310 e DOW 2B610 obtiveram melhor resposta com ureia revestida e nicosulfuron $(5,4 \%,-27,4 \%$ e $-7,33 \%)$ respectivamente. Caso diferente foi observado aos $35 \mathrm{DDH}$, em que os híbridos DOW 2B610, MG 30A37 e AS 1633 obtiveram melhores respostas com a associação de ureia e nicosulfuron $(-3,32 \%,-3,55 \%, 0,64 \%)$, e o híbrido DKB 310 respondeu melhor a associação ureia revestida e nicosulfuron $(-11,0 \%)$ (Tabelas 1 e 2). Estudo com a tolerância de híbridos de milho a doses de nicosulfuron, também mostraram efeito significativo na altura de plantas (Cavalieri et al., 2008).

A associação de nicosulfuron e ureia ou ureia revestida não afetou as variáveis diâmetro de colmo, número de fileiras, comprimento de espiga e semente, mas nota-se que para a maioria das variáveis os valores máximos obtidos foram pela associação entre ureia revestida e nicosulfuron (Tabela 1 e 2). Também, nessas variáveis a combinação dos fatores não diferiu das testemunhas estatisticamente para os híbridos DKB 310, DOW 2B610 e MG 30A37 (Tabelas 1 e 2). Somente para o híbrido AS 1633 que o comprimento de semente e espiga nas testemunhas diferiram à combinação dos fatores, sendo as testemunhas superiores (Tabela 2). Somente para o híbrido DOW 2B610 que a associação de nicosulfuron e as fontes nitrogenadas influenciou no peso de 500 sementes, destacando a ureia aplicada quatro dias antes da aplicação do herbicida (DAH) com a melhor resposta do híbrido $(0,1404 \mathrm{~kg})$ (Tabela 2$)$. 


\section{(2)agrartar}

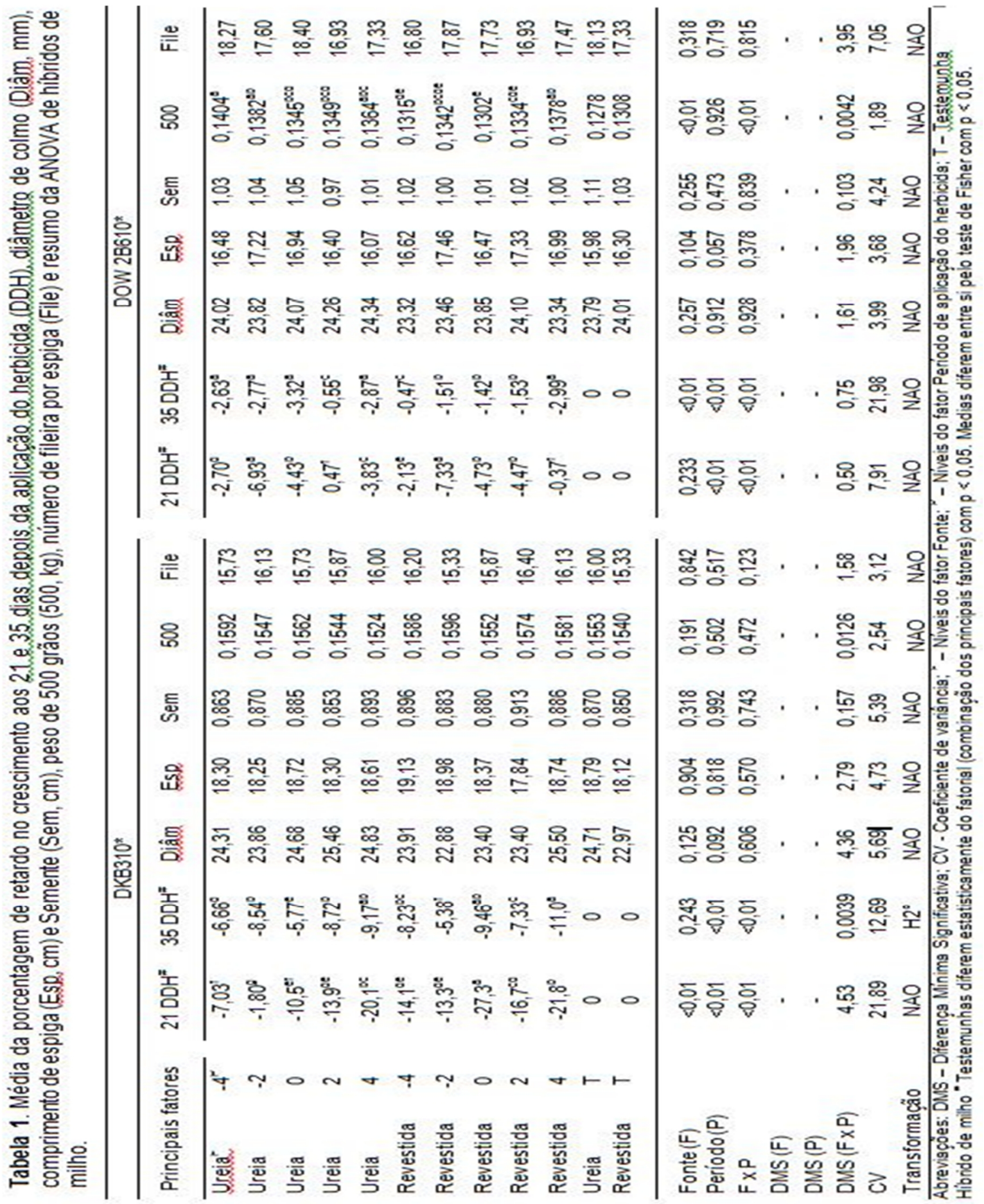






Nota-se que na produtividade de grãos para maioria dos híbridos, incremento com a aplicação das fontes no intervalo de dois DAH a dois DDH (Figura 1). A produtividade tende a diminuir após aplicação de ambas as fontes dois DDH para AS 1633 e DOW 2B610, sendo o contrário observado para DKB 310 (Figura 1). O híbrido MG $30 A 37$ foi o único a apresentar respostas opostas entre as fontes nitrogenadas, ou seja, com a ureia a produtividade tende a diminuir após dois $\mathrm{DDH}$ e ureia revestida tende a aumentar (Figura 1). Somente as testemunhas dos híbridos MG 30 A37 e DKB 310 foram inferiores significativamente à combinação dos fatores na produtividade final de grãos (Figura 1). Apesar de que o estudo de hormesis ser embasado em subdoses (Belz e Duke, 2014), pode-se afirmar que ocorreu uma característica de hormesis em que essa associação de herbicida e nitrogênio estimulou as plantas em aumentar a produção de grãos, mesmo não sendo subdose. Possivelmente, a tolerância apresentada pelos híbridos está relacionada com a 
introdução de novas tecnologias nos híbridos, assim tornado a enzima acetolactato sintase mais tolerante à molécula de nicosulfuron. Essa tolerância pode ser a substituições de genes na enzima (Fisher et al., 2000; Beckie e Tardif, 2012; Yu e Powles, 2014) ou a ação da enzima esteja alta na utilização de FAD (dinucleótido de flavina e adenina), para que a estrutura da enzima tenha mais estabilidade (Schloss et al., 1988; Schloss, 1989).

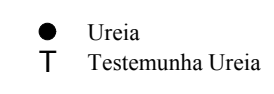

DKB 310

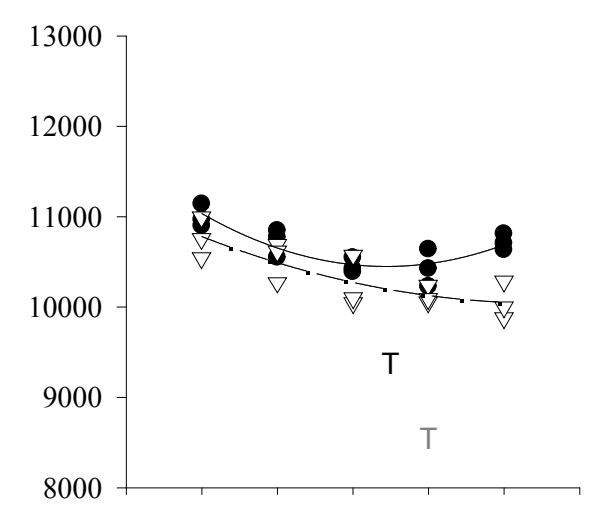

AS 1633

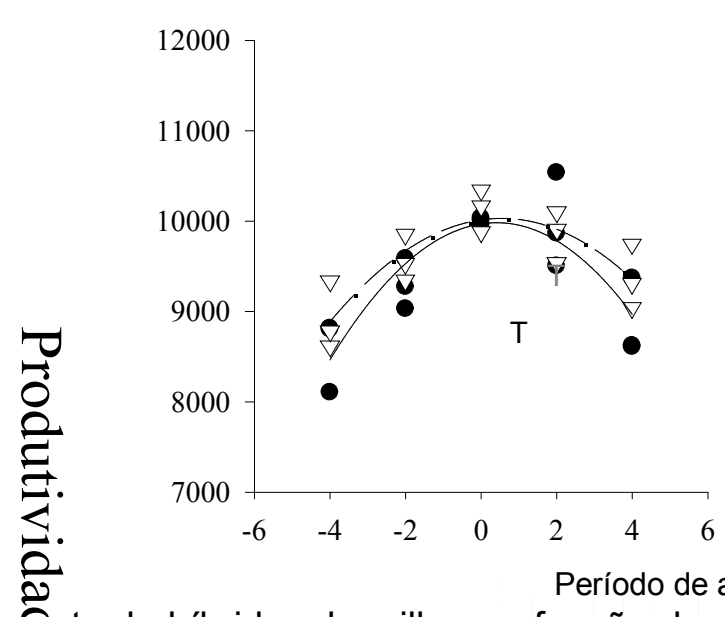

$\begin{array}{ll}\nabla & \text { Ureia revestida } \\ \top & \text { Testemunha Revestida }\end{array}$

\section{MG 30A37}

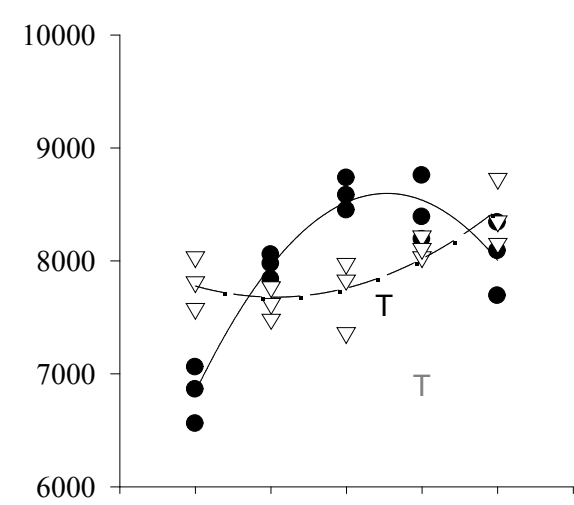

DOW 2B610

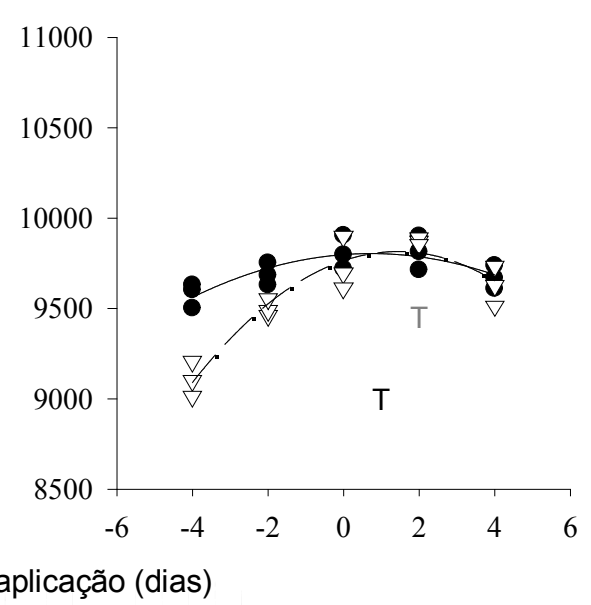

Figura 1. Resp्̧థsta de híbridos de milho em função do período de aplicação (em dias) de fontes nitrogenadas de acordo coma aplicação de nicosulfuron no estágio fenológico de milho V4, Jataí-GO, 2018. DKB 310 Revestida $\left(Y=8,986 x^{2}+90,844 x+10.272,561 ; R^{2}=0,826\right)$, Ureia $\left(Y=24,648 x^{2}+43,083 x+10.468,414 ; R^{2}=\right.$ 0,861); $M G$ 30A37 Revestida $\left(Y=22,281 x^{2}+84,999 x+7.760,16 ; R^{2}=0,82\right)$, Ureia $\left(Y=-68,624 x^{2}+145,812 x\right.$ + 8.520,018; $\left.R^{2}=0,95\right) ; A S 1633$ Revestida $\left(Y=-55,950 x^{2}+59,036 x+10.015,046 ; R^{2}=0,843\right)$, Ureia $(Y=-$ $\left.78,355 x^{2}+62, \overrightarrow{3} 6 x+9.970,261 ; R^{2}=0,851\right)$; DOW 2B610 Revestida $\left(Y=-24,628 x^{2}+70,275 x+9.765,247\right.$; $\left.R^{2}=0,948\right)$, Urea $\left(Y=-10,916 x^{2}+15,479 x+9.798,631 ; R^{2}=0,787\right)$.

\section{Conclusãỡ̆}

A assoĉ̉ação de nicosulfuron e ureia ou ureia revestida mostrou efeito positivo e significativo no crescimento vegetativo das plantas de milho, para os híbridos DKB 310, MG 30A37 e DOW 2B610. Essa associação apresentou melhor benefício com aplicação de ureia ou ureia revestida no intervalo de dois dias antes ou após à aplicação de nicosulfuron.

\section{Referências}

Beckie, H.J., \& Tardif, F.J. (2012). Herbicide cross resistance in weeds. Crop Protection, 35(1), 15-28. 
Belz, R.G., \& Duke, S.O. (2014). Herbicides and plant hormesis. Pest Management Science, 70(5), 698-707.

Cavalieri, S.D., Oliveira Júnior, R.S., Constantin, J., Biffe, D.F., Rios, F.A., \& Franchini, L.H.M. (2008). Tolerância de híbridos de milho ao herbicida nicosulfuron. Planta Daninha, 26(1), 203-214.

EWRC. European Weed Research Council. (1964). Report $f 3^{\text {rd }}$ and $4^{\text {th }}$ meetings of EWRC - Committee of Methods in Weed Research. Weed Research, 4(1), 88.

Fischer, A.J., Bayer, D.E., Carriere, M.D., Ateh, C.M., \& Yim, K.O. (2000). Mechanism of resistance to bispyribac-sodium in an Echinochloa phyllopogon accession. Pesticide Biochemistry Physiology, 68(3), 156165. https://doi.org/10.1006/pest.2000.2511

Fonné-Pfister, K., \& Kreus, K. (1990). Ring-methyl hydroxylation of chlorotiuron by inducible cytochrome P-450 dependent enzyme from maize. Phytochemistry, 29(9), 2793-2796. https://doi.org/10.1016/00319422(90)87077-8

Gallaher, K., Muller, T.C., Hayes, M.R., Schwartz, O., \& Barrett, M. (1999). Absorption, translocation and metabolism of primisulfuron and nicosulfuron in broadleaf signalgrass (Brachiaria platyphylla) and corn. Weed Science, 48(1), 8-12. https://doi.org/10.1017/S0043174500090585

Gerhardt, M. (2016). Uma história ambiental da modernização da agricultura: o norte do Rio Grande do Sul. Revista História: Debates e Tendência, 16(1), 166-180.

Guerra, N., Maciel, C.D.G., Oliveira Neto, A.M., Poletine, J.P., Lima, G.G.R., Sola Júnior, L.C. (2010). Seletividade de formulações de nicosulfuron para híbridos de milho em função da época da adubação nitrogenada. Revista Brasileira de Herbicidas, 9(3), 89-99. https://doi.org/10.7824/rbh.v9i3.86

Heap, I. (2021). The International survey of herbicide resistant weeds. Disponível em: $<$ http://www.weedscience.org/>. Acesso em: 10/04/2021.

Hernández, M.J., León, R., Fischer, A.J., Gebauer, M., Galdames, R., \& Figueroa, R. (2015). Target-site resistance to nicosulfuron in johnsongrass (Sorghum halepense) from Chilean corn fields. Weed Science, 63(3), 631-640. https://doi.org/10.1614/WS-D-14-00167.1

Khan, N.W., Khan, N., \& Khan, I.A. (2012). Integration of nitrogen fertilizer and herbicides for efficient weed management in maize crop. Sarhad Journal of Agriculture, 28(3), 457-463. https://www.cabdirect.org/cabdirect/abstract/20123342742

Kreus, K., \& Fonné-Pfister, K. (1992). Herbicide-insecticide interaction in maize: Malathion inhibits cytochrome P-450 dependent primisulfuron metabolism. Pesticide Biochemistry and Physiology, 43(3), 232-240. https://doi.org/10.1016/0048-3575(92)90036-Y

López-Ovejero, R.F., Fancelli, A.L., Dourado Neto, D., García y García, A., \& Christoffoleti, P.J. (2003). Seletividade de herbicidas para a cultura de milho (Zea mays) aplicados em diferentes estádios fenológicos da cultura. Planta Daninha, 21(3), 413-419. https://doi.org/10.1590/S0100-83582003000300009

Môro, F.V., \& Damião Filho, C.F (1999). Alterações morfo-anatômicas das folhas de milho submetidas à aplicação de nicosulfuron. Planta Daninha, 17(3), 331-337. https://doi.org/10.1590/S010083581999000300001

Nicolai, M., López Ovejero, R.F., Carvalho, S.J.P., Moreira, M.S., \& Christoffoletti, P.J. (2006). Efeitos da adubação nitrogenada em cobertura sobre a seletividade de herbicidas à cultura do milho. Planta Daninha, 24(2), 279-286. https://doi.org/10.1590/S0100-83582006000200010

Santos, H.G., Jacomine, P.K.T., Anjos, L.H.C., Oliveira, V.A., Lumbreras, J.F., Coelho, M.R., Almeida, J.A., Cunha, T.J.F., \& Oliveira, J.B. (2013). Sistema brasileiro de classificação de solos. $3^{a}$. ed. Brasília, DF: Embrapa.

Schloss, J.V. (1989). Modern aspects of enzyme inhibition with particular emphasis on reaction intermediate analogs and other potent, reversible inhibitor. In: Boger, P., \& Sandmann, G. Target sites of herbicide action. CRC Press, Boca Raton, FL, 165-245.

Schloss, J.V., Ciskanik, L.M., \& Vandyk, D.E (1988). Origin of the herbicide binding site of acetolactate synthase. Nature, 331(1), 360-362. https://doi.org/10.1038/331360a0 
Spatt, L.L., Dornelles, S.H.B., Sanchotene, D.M., Brum, A.B., Caloto, B.W., \& Scherer, M.B. (2016). Low-level resistance of Cyperus iria L. to ALS-inhibiting herbicides occurring in the state of Rio Grande do Sul. Cientifica, 44(4), 532-537. http://doi.org/10.15361/1984-5529.2016v44n4p532-537

Timossi, P.C. (2009). Manejo de rebrotes de Digitaria insularis no plantio direto de milho. Planta Daninha, 27(1), 175-179. https://doi.org/10.1590/S0100-83582009000100022

Timossi, P.C., Silva, U.R., Lima, S.F., \& Almeida, D.P. (2016). Eficácia de nicosulfuron e tembotrione no controle de Pennisetum setosum. Global Science and Technology, 9(1), 1-6. https://rv.ifgoiano.edu.br/periodicos/index.php/gst/article/view/779/489

Yu, Q., \& Powles, S.B. (2014). Resistance to AHAS inhibitor herbicides: current understanding. Pest Management Science, 70(9), 1340-1350. https://doi.org/10.1002/ps.3710 